\title{
ATTENTION DEFICIT HYPERACTIVITY DISORDER INTERVENTION: STRATEGIES \& COUNSELLING TIPS FOR PRIMARY SCHOOL TEACHERS.
}

\author{
ABIKWI M. I. PhD. \\ Edo State Teaching Service Commission. \\ Benin City. Edo State
}

\begin{abstract}
This paper addresses attention deficit hyperactivity disorder intervention strategies for primary school teachers. Wrong labelling of children with attention deficit hyperactivity disorder has given rise to this paper. Hitherto not much attention has been given to the pupils who manifest symptoms of this chronic behavioural disorder even when they are going through difficulties in the learning process. The need for teachers' intervention strategies has been extensively discussed in this paper with a view of developing an intervention programme in other to promote care and support for the pupils who manifest symptoms of ADHD. It is recommended among other things that teachers' knowledge should be enhanced to equip them to enable them give care and support to ADHD pupils in the learning process and make referral when necessary. There is an urgent need to include in the curriculum of Guidance and Counselling in Nigeria institutions Attention Deficit Hyperactivity Disorder its symptoms and management strategies. Also Counselling units should be established in primary schools in line with the provisions in the National policy on Education this will reduce most of the problems ADHD pupils face during learning process.
\end{abstract}

Key words: Attention Deficit/hyperactivity Disorder (ADHD), Disruptive Behaviour Disorder Rating Scale (DBD), Inattention, Hyperactivity/Impulsivity, Primary school pupils

\section{Introduction}

Attention Deficit Hyperactive/Impulsivity Disorder is a chronic incapacitating disorder, which may have impact on many aspects of the individuals' life including academics difficulties, social skills problem and strained relationships. It is the most common child psychiatric disorder in Europe and the USA. Taylor (1995) asserted that an estimated 
3-6\% of the general population of school-age pupils manifest significant ADHD symptoms.

According to American Psychiatric Association (1994) Attention Deficit/Hyperactive Disorder refer to a developmental disorder characterised by a persistent pattern of inattention and or hyperactivity/impulsivity that is more frequent or severe than is typically observed in individual at a comparable level of development.

According to Uwe (2000), Agbu (2003), and Harpin (2005), ADHD may affect all aspects of a pupil's life; its impact may not only be on the child and his/her parents but also on teachers and peers, thereby causing disturbances in the school settings. Some pupils may exhibit traits that are explorative, inquisitive, playful, restless, impulsive and over active than others. If these problems are not known such pupils might become problematic to themselves, their teachers, parents and siblings. One can just imagine the most difficult environment for a pupil who has difficulty sitting still, difficulty paying attention and loves to talk excessively even when no one is seem to be listening. Imagine that this pupil had to go into this environment every day and was expected to perform successfully.

According to Hinshaw (1994) Pupils with untreated ADHD with other conduct disorders may experience drug abuse, develop low selfesteem and depression and other antisocial behaviour, injuries of all sorts as they grow older, for many of them the impact continues till adulthood. (National Institute of Health).

The "classroom setting" has difficulty for the ADHD pupils because of the many distractions, yet pupils are told to 'sit still', don't talk", "don't move"; "pay attention to all the lessons whether it is boring or not", "keep on the task until the work is done". None of these things come easily to ADHD pupils, yet every day the parents send them off to school and the teacher awaits them with a pack full of the 'don' ts'.

The idea behind teachers' intervention is that even though there is something wrong with the brain of the child who has been diagnosed with ADHD, when the child is adequately motivated, s/he can in part make up for any deficit. In other words a pupil who is suffering from hyperactivity will try his best to sit still, listen and think before acting.

More often one therapy, treatment or intervention will not alleviate ADHD symptoms in a pupil. It is better to have a combination of tools and positive intervention that can make remarkable differences in these pupils and their lives in our society. ADHD children are all over the place and there is need to make conscious effort to assist them to make living and learning less stressful. 
Teachers are concerned why children become restless and too playful when given a task. Many of these signs may be symptoms of ADHD, unless a proper diagnosis is made, teachers may continue to manage the situation on their own without success. ADHD manifest in pupils usually from two (2) years and before the age of seven. These symptoms of ADHD can linger on to adulthood.

\section{Types of ADHD.}

There are three types of ADHD. They are Inattention, Hyperactivity/Impulsivity and Combined type. According to the Diagnostic and Statistical Manual of Mental Disorders (4th edition) (DSMIV) (American Psychiatric Association, 1994) diagnosed types of Attention-Deficit Hyperactivity/Impulsivity Disorder (ADHD) according to the following criteria:

A. Either 1 or 2 should be present

Inattention type:

(1) Six (or more) of the following symptoms of inattention have persisted for at least 6 months to a degree that is maladaptive and inconsistent with developmental level:

\section{Inattention}

i. fails to give close attention to details or makes careless mistakes in school work or other activities

ii. has difficulty sustaining attention in tasks or play activities

iii. does not seem to listen when spoken to directly

iv. does not follow through on instructions and fails to finish schoolwork, chores, or duties in the workplace (not due to oppositional behaviour or failure to understand instructions)

v. has difficulty organizing tasks and activities

vi. avoids, dislikes, or is reluctant to engage in tasks that require sustained mental effort (such as schoolwork or homework)

vii. loses things necessary for tasks or activities (e.g., toys, school assignments, pencils, books, or tools)

viii. easily distracted by extraneous stimuli

ix. forgetful in daily activities

(2) Six (or more) of the following symptoms of hyperactivityimpulsivity have persisted for at least 6 months to a degree that is maladaptive and inconsistent with developmental level: 


\section{Hyperactivity}

i. fidgets with hands or feet or squirms in seat

ii. leaves seat in classroom or in other situations in which remaining seated is expected

iii. runs about or climbs excessively in situations in which it is inappropriate (in adolescents or adults may be limited to subjective feelings of restlessness)

iv. has difficulty playing or engaging in leisure activities quietly

v. often "on the go" or often acts as if 'driven' by a motor

vi. talks excessively

\section{Impulsivity}

i. blurts out answers before questions have been completed

ii. has difficulty awaiting turn

iii. interrupts or intrudes on others (e.g. butt into conversations or games)

Three types of diagnostic categories emerged as follows:

1. Attention-Deficit/Hyperactivity Disorder, Combined Type: if both Criteria A1 and A2 are met for the past 6 months

2. Attention-Deficit/Hyperactivity Disorder, Predominantly Inattentive Type: if Criterion A1 is met but Criterion A2 is not met for the past 6 months

3. Attention-Deficit/Hyperactivity Disorder, Predominantly Hyperactive-Impulsive Type: if Criterion A2 is met but Criterion A1 is not met for the past 6 months

The American Psychiatric Association (APA) has identified that parents and teachers are the ones who seek help for about $20 \%$ of children population diagnosed and exhibit the problems of ADHD. There are no reliable laboratory tests that can accurately diagnose the symptoms nor is there blood test for ADHD. For a pupil to be diagnosed as having ADHD Inattention type the child most manifest six (6) out of the nine (9) symptoms stated above in at least two settings preferably at home and at school. Pupils who manifest these symptoms will basically not be able to complete a given task without making what appear to be silly mistakes because s/he did not pay attention to the instructions. Such pupils are likely to loose materials such as pencils, books erasers that are meant for a particular task. Irrelevant things often distract a pupil that has ADHD 
inattention type because of these distractions s/he cannot complete a given task.

They carry these behavioural problems into the school. While in school, they equally pose problems to their teachers and peers. They lack self-control and are, sometimes aggressive, with their attention span being very short. ADHD pupils in school need to pay attention to the right thing, at the right time until they are finished.

\section{Effects of ADHD}

ADHD is a particularly serious problem because pupils with core difficulties of inattentions, hyperactivity/impulsivity may lead to poor attainment in school. Impulsivity and hyperactivity may lead to difficulties making and maintaining appropriate peer relationship and developing a supportive group. According to Hinshaw (1994) when children with ADHD become aware of their difficulties with regulating attention activity and impulsivity and the failure that these difficulties lead to within the family, peer group and school, pupils with ADHD may develop low self esteem and depression. The earlier it is diagnosis the better the chance of avoiding complicating difficulties.

The effect of ADHD can be categorized as follows

\section{Emotional Disorder:}

More than half of pupils with attention-deficit hyperactivity disorder have accompanying disorders, including anxiety, depression, and conduct disorders. (Children with ADHD who experience anxiety or depression are also more likely to suffer from low self-esteem). (Hinshaw 1994).

\section{Social Problems:}

The ADHD pupil's relationship with others is unpredictable, and s/he is often unhappy from a very young age. Meyer (2001) stated that 50\% $70 \%$ of pupils diagnosed with ADHD will have problems related to social adjustment, particularly an aggressive ADHD child, will have trouble getting along with others and is less liked by his or her peers. She added that ADHD children with the inattentive subtype only are more likely to spend time alone. Pupils with the combined subtypes tend to have different problems. 


\section{Learning Problems:}

Although speech and learning disorders are common in children with ADHD, the disorder does not affect intelligence. People with ADHD span the same 1Q range as the general population. In an extensive research conducted over 5 to 10 years demonstrated that as many as 35\% - 50\% of all children with ADHD also have other specific learning disabilities in the areas of reading, writing, language, or mathematics (De La Paz, 2001; Hook \& DuPaul, 1999; Kim \& Kaiser, 2000; Zentall, 1993; Dykman, Akerman, \& Raney, 1994). One study suggested, however, that $90 \%$ of ADHD children were underachievers and that half were held back at least once. Some evidence suggests that inattention may be a major factor in low academic performance in these children. Furthermore, Barkley, 1998; Green \& Chee, 1997 in their research showed that although these students are most often of average to above-average intelligence, they are also at a very high risk for academic underachievement, especially if their ADHD is unrecognised and not managed appropriately.

\section{Effect on Peers:}

Peers of ADHD pupils have particular difficulties, and are also at risk for psychological impairment, depression, drug abuse, and language disorders. The non-ADHD peer does not have the control the teacher has in the management of the ADHD pupil's behaviour and is very likely to feel alienated and alone. Non-ADHD pupils are often victimized by ADHD peers who may be demanding or bullying. A peer who is not given attention in his or her own right may begin to imitate undesirable behaviours or to act out negatively in other ways. It is very important to make the school peers equally vital to the teachers functioning.

\section{The Role of the Teacher.}

- The teacher can help the ADHD child by talking to the parents.

- The teachers can develop a positive and not adversarial relationship with the pupil and be prepared to assist.

- The teacher must acknowledge both child and parent's situation.

- Frequent briefing and conversations with parents can be helpful. It can lead to co-ordination of efforts particularly if they provide reciprocal information about progress or setbacks.

- Ensure that the ADHD pupil is placed in the front seat away from distractions. 
- Love and care for the ADHD pupils and engage the ADHD pupils with other intervention strategies.

- The learning environment should be very conducive for the ADHD pupil. The classroom should be free from distracting objects.

- Vary the instructional methods to include the ADHD pupils as well as other pupils in the class.

- The teacher should be aware of co-existing conditions of the pupils such as learning disabilities as well as reinforcing the importance of classroom and instructional structure.

\section{Instructional Strategies for ADHD Intervention:}

(A) Giving Directions

The teacher has to maintain eye contact during verbal instruction. Directions need to be given clearly and concisely through multiple channels. Make sure the pupils comprehend the instructions before beginning the task. Repeat instructions in a calm, positive manner whenever necessary. For instance, the teacher should clearly give the directions as well as write it or represent it in pictorial forms. Finally ask the pupil to repeat it to you.

(B) Giving Assignments.

In giving assignments the teacher should make sure that the pupil is writing down assignments correctly each day. When a pupil is in-capable due to age or other factors, the teacher should assist in providing a record of assignments for the pupil to take home, modify assignments to suit the capacity of the pupil and give extra time for certain tasks. Pupils with ADHD may work slowly do not penalize them for the needed extra time. The teacher should bear in mind that stress, frustration; fatigue can set in quicker than expected with ADHD pupils. Develop a plan to determine specified strengths and weakness of pupils.

\section{(C) Assistance}

The teacher can help the ADHD pupils feel comfortable asking for assistance. To effectively do this the teacher should apply the wide range of teaching methods to be class centred instead of individual centred in other words let your instructional method apply to all pupils do not single out ADHD pupils. Develop and discuss with the ADHD pupils private cues that can be used 
during a given lesson. For instance the teacher can quietly touch the pupil's shoulders to remind s/he to get back or refocus on task.

\section{(D) Test Taking}

Pupils with ADHD may need more time to complete tests. The teacher must ensure that the directions are clearly understood and the pupil is able to carry out the given task. Some pupils may need to be clarified while others need modification in the way the test is to be done. Some test could be done orally while others could be written. Whatever method the teacher deems fit to use, unique and individual needs must be considered at all times.

(E)

\section{Self Monitoring}

The teacher should ensure that most programmes are pupils centred. Pupils with ADHD can often participate in planning for improvement in their own behaviour. Encourage them to experience more ownership for positive changes and also make effort to accomplish given tasks. Pupils need to understand or be aware of the problem behaviour and the control they can exhibit to improve the situation.

To begin this intervention, the teacher would select behaviour and explain to the pupils the nature of the problem and what will constitute improvement. (For example a pupil who never completes a given task or activity). Teachers can assist the pupils to develop a rating scale to rate behaviour and document improvement. The pupils will need to learn how to use the rating scale, which should be appropriate to the pupil's age. Every completed task is scored fully (10 marks) while uncompleted task is scored half (5marks) and a task not done gets zero (0). At the end of the day, the total scores are recorded. For a high score the pupil could get a praise e.g. well done, you have done very well etc or a packet of biscuit as it applies to the age or both.

Self-monitoring can be gradually faced out as the pupil makes progress in that behaviour while in other circumstances self monitoring may continue for a longer time.

\section{Counselling Tips for Teachers}

A pupil with ADHD can present unique challenges in the classroom, ADHD symptoms can be a source of frustration to the pupils. There are 
ways the teacher can help ADHD pupils' to improve the educational experience and control the symptoms of this disorder. The teacher should work on the most difficult concept/lessons early in the day. Give direction for one assignment at a time instead of lumping assignment together or giving direction to multiple tasks at once. Break work up into smaller segments and sprints, and allow the ADHD pupils frequent break times to move around inside and outside the classroom. This may vary from a daily outside walk, doing errands around the building, to classroom stretching exercises.

The teacher should ensure that other pupils are friendly with the ADHD pupil especially during group work. ADHD pupils should not be isolated. Ensure that classroom environment is organized and stimulating by clearly defining rules and expectations. ADHD pupils should not be isolated rather seating should be preferential with pupil seating in front or at the centre near the teacher and away from distracting objects and pupils. Pupils who present as good role models should seat near by. The teacher should vary the pace and type of activity to maximize the pupils attention. It will be unwise to spend too much time in low energy activities. The teacher should engage the ADHD pupil in interesting activities in which they will work with their hands most of the time. Finally the teachers must not give up on any pupil who manifest symptoms of ADHD.

Pupils who manifest symptoms of ADHD will need emotional and social support. They can pose a challenge to their parents, teachers and other pupils; their self esteem may be affected. These pupils may also lack positive experience with accomplishing given tasks and relationships.

The following can be helpful in providing emotional support for ADHD pupils in the classroom:

1. The teacher should identify and focus on the pupil's strengths and talents instead of on the pupils' shortcoming and negative behaviour. Pupils' positive qualities should be nurtured in every setting. The strength of an ADHD pupil lies in what they can do well and on time. Stress less on their failures or the task they could not complete.

2. The teachers should offer sincere praise for accomplishment. A pupil who has done well expects to hear comments like, you have done well, well-done, keep it up, the best is coming your way. 
3. Help the ADHD pupils to visualize a positive future and a career in which their talents will be explored.

4. Encourage participation and co-operative grouping instead of seeking for the winners or losers.

5. Help them to understand themselves and the effects of the disorder, boost their self-esteem. They need to see themselves as other pupils without ADHD.

6. Put in place formal counselling as the need may arise.

7. Ensure a "team effort" of support from all adults who play key roles in the pupil's life e.g. Parents, Educators, Health care providers, Siblings and so on.

8. Let every one appreciate the condition of the ADHD pupil and give assistance in difficult tasks.

\section{Conclusion.}

ADHD is a commonly diagnosed behavioural disorder of childhood that represents a major health problem. Pupils with this disorder usually have pronounced difficulties and impairments resulting from the disorder across multiple settings. Although an independent diagnostic test for ADHD does not exist, evidence supporting the validity of the disorder can be found. The teachers are expected to apply these skills in assisting the pupil who may manifest the symptoms of ADHD.

Teachers and School officials should also be educated and involved in the process. In addition to behaviour therapy for the pupil, school intervention may help ADHD pupils and their parents and siblings cope with the emotional conflicts that nearly always arise in the lifelong management of the condition.

Although an independent diagnostic test for ADHD does not exist, evidence supporting the existence of the disorder has been established (Egbochuku \& Abikwi 2006).

Given that the related "medical" fields have acknowledged their limitations in diagnosing ADHD and that the school setting is the context within which the vast majority of ADHD behaviours are recognised as being problematic, it is most typically the school psychologist who enacts the primary role of diagnostician for this condition.

Subsequently, it is incumbent that school psychologist have some valid and reliable means of structuring and conducting these evaluations. 


\section{Recommendations}

- Teachers should explore avenues to learn more about ways of identifying pupils who manifest the symptoms of ADHD to enable them make proper referral.

- The knowledge of teachers should be updated through organised workshops, in-service training on how and what to do when pupils manifest defiant behaviour.

- Support group programmes should be put in place where government agencies and other reputable health organizations can educate teachers' and other stakeholders on management of Attention Deficit Hyperactivity Disorder.

- Teachers are encouraged to maintain a closer relationship with parents and other professionals' bodies' e.g. educational psychologist, paediatricians and child psychiatrist to increase the knowledge base of teachers and reduce the incidence of misdiagnosis..

- Teachers should not punish or bully pupils with ADHD symptoms rather they should be encouraged and given the needed support, for educational survival skills to foster their selfconcept and improve their academic performance.

- Colleges of Education and Universities should organize programmes on ADHD and include such programme in the school curriculum.

- Counsellors should be trained in behavioural interventions which have no side effect in the treatment of ADHD.

- It is recommended that an ADHD resource centre be developed by the government for training, information, counselling and rehabilitation of pupils who are infected or affected with attention deficit hyperactivity disorder. At such a centre the latest research on ADHD should be available to teachers.

- There is an urgent need to include in the curriculum of Guidance and Counselling courses in Attention Deficit Hyperactivity Disorder; its symptoms and management.

- Counselling units should be established in primary schools in line with the provisions in the National Policy Education. This will reduce most of the problems ADHD pupils face during learning tasks as it will be easy to make referral for adequate management. 


\section{References:}

Adam. Inc. Well-connected series (2003, December 15). Retrieved June 7, 2005, from http:/ / www.heaithandage.com/Home.

Agbu J. O., (2003). Assessment and management of attentiondeficit/hyperactivity disorder of children, In Nnachi, R. O. and Ezeh, P. S. (Ed) The Behaviour of the Nigeria Child. A publication of the Nigerian Society for Educational Psychologist. (NISEP).

American Academy of Paediatrics (2000). Clinical practice guideline: Diagnosis and evaluation of the child with attention-deficit/hyperactivity Disorder. American Academy of Paediatrics. 1158-1170:

American Psychiatric Association (1994). Diagnostic and statistical manual of mental disorders: DSM-IV (4th ed.) Washington, D. C: Author.

Awake, (1997) Watchtower, Bibles \& Tracts Society "Living with a learning disability" Feb. 22nd, New York. Inc. 25 Columbia Height, Brooklyn. Author.

Barkley, R. A., (1998). Handbook of Attention Deficit Hyperactivity Disorder. (2nd ed.). New York: The Guilford Press.

Bowley, B., Walther, E. (1992). Attention hyperactive deficit disorders and the role of the elementary school counsellor. Elementary School Guidance \& Counselling. 39- 46.

De'LaPaz, S. (2001). 'Teaching writing to students with attention deficit disorders and specific language impairment', The Journal of Educational Research. 95, 95-105.

Dykman, R.A., Akerman, P.T., \& Raney, T.J. (1994). Assessment and Characteristics of Children with Attention Deficit Disorder. Prepared for the Office of special Education Programs, Office of Special Education and Rehabilitative Services, U.S Department of Education.

Egbochuku, E. O., \& Abikwi, M. I., (2006). The prevalence of attention deficit hyperactivity disorder (ADHD) among primary school pupils of Benin Metropolis, Nigeria. Journal of Human Ecology. (In Press).

Green, C. and Chee, K. (1997). Understanding attention deficit hyperactivity disorder. Sydney: Doubleday.Hinshaw, S. P., Melnick, S. M., (1995). Peer relationships in children with attention deficit hyperactivity disorder with and without comorbid aggression. Developmental Psychopathology. 7, 627-647.

Hook, C. L. and DuPaul, G. J. (1999) 'Parent tutoring for students with attention deficit/hyperactivity disorder: Effects on reading 
performance at home and school', School Psychology Review 28, 6071.

Kim, O. H. and Kaiser, A. P. (2000) 'Language characteristics of children with ADHD', Educational Resources Information Centre (ERIC) Digest (1989). Adam. Inc. wee- connected series (2003, December 15). Retrieved June 7, 2005, from http://www.healthandage. com/Home.

Martins, G. L., (998), The Attention Deficit Child, Colorado Springs Chariot Victor publishing, 1998

McArdle, P. (2004). Attention deficit hyperactivity disorder and life-span development. British Journal of Psychiatry. 184, 486-469

Mehl-Madrona, L. (2000) Educational Interventions and other behavioural techniques for ADHD. htto//www.healingarts.org/chilren/ADHD/educational.htm Retrieved August 25, 2005.

Meyer, A. (1998). Attention-deficit/hyperactivity disorder among North Sotho speaking primary school children in South Africa: Prevalence and sex ratios. Journal of Psychology in Africa. 8, 186-195.

Meyer A., Eilertsen D., Sundet J. M, Tshifularo J \& Sagvolden T. (2004). Cross-cultural similarities in ADHD-like behaviour amongst South African primary school children. South African Journal of Psychology 34 (1), 122-132.

Nadeou K. \& Dixon E. (1993). Learning to slow down and pay attention. Amandale, V. A., Chesapeake Psychological Publication. National Institute of Mental Health (2002), Breaking ground through: The Strategic Plan for Mood Disorders, Research of NIMH. (Publication No0507-B-05). Retrieved January 2003 via GPO Access: http//pul.access.gpo.gov/GPO/ LP20906

National Institute of Mental Health (2002), Breaking ground through: The Strategic Plan for Mood Disorders, Research of NIMH. (Publication No0507-B-05). Retrieved January 2003 via GPO Access: http//pul.access.gpo.gov/GPO/ LP20906

Pelham, W.E Jr, Wheeler, T., \& Chronis, A., (1998). Empirically supported psychological treatments for attention deficit hyperactivity disorder. Journal of Clinical Child Psychology. 27, 190-205

Taylor, E., Chadwick O, Heptinstall E, \& Danclats M., (1996). Hyperactivity and conduct problems as risk factors for adolescent development. Journal of the American Academy of Child $\mathcal{E}$ Adolescent Psychiatry .35, 1213-1226. 
Uwe, E., (2000). Early identification and management strategies of attention deficit/hyperactive disorder in children: The Exceptional Child. 4, 1, 30-33.

Weiss. S., Behaviour Management strategies for ADD (ADHD) child. The ADD ADHD Newsletter. June 2005

World Health Organisation (1993). The ICD-10 Classification of mental and behavioural disorders: Clinical Descriptions and Diagnostic Guidelines. Geneva: Author.

Zental, S. S., (1993). Research on the educational implications of attention deficit hyperactivity disorder. Exceptional Children, 60, 143-153. 